\title{
Extended adverse effects of cyclophosphamide on mouse ovarian function
}

\author{
Jihyun Kim and Sooseong You ${ }^{*}$ (D)
}

\begin{abstract}
Purpose: Most patients with cancer undergo multiple administrations of anticancer drugs during treatment, resulting in chronic impairment of their reproductive health. As improved treatment options increase cancer survival, it has become increasingly important to address fertility issues in cancer survivors. In this study, we examined the pathophysiological effects of multiple exposures to cyclophosphamide (Cy) on the ovaries of mice and their underlying molecular mechanism.

Methods: Female C57BL/6 mice were intraperitoneally injected with 100 mg/kg Cy six times over 2 weeks; 4 weeks later, the mice were sacrificed and their ovaries, sera, and oocytes were collected for histological observation, measurement of anti-Müllerian hormone levels, and assessment of oocyte quantity and quality in response to hormonal stimulation. Gene expression changes in Cy-treated ovaries were examined by microarray and bioinformatics analyses.

Results: After repeated Cy exposure, the anti-Müllerian hormone level was decreased, and follicle loss and impairments in the quality of oocyte were irreversible. The expression levels of genes involved in folliculogenesis, oogenesis, and zona pellucida glycoprotein transcription displayed sustained alterations in Cy-exposed ovaries even after 4 weeks.

Conclusion: The adverse effects of Cy on ovarian function and oocytes remained even after chemotherapy was complete. Therefore, strategies to prevent ovarian damage or restore ovarian function after treatment are required to safeguard the fertility of young cancer survivors.
\end{abstract}

Keywords: Cyclophosphamide, Chronic side effect, Ovarian dysfunction, Oocyte, Bioinformatics analysis, Mice

\section{Background}

Most patients with ovarian cancer are administered multiple rounds of chemotherapy, the off-target toxicities of which can result in dangerous side effects that must be addressed [1]. Anticancer agents have complex mechanisms of action and their effects depend on their drug type, dose, and therapeutic duration [2]. During cancer treatment, the same drugs are administered every $2-3$ weeks for more than four cycles; this repeated exposure can severely affect the quality of life of patients [3]. In

\footnotetext{
* Correspondence: ethink33@kiom.re.kr

Clinical Medicine Division, Korea Institute of Oriental Medicine, 1672

Yuseongdae-ro, Yuseong-gu, Daejeon 34054, Republic of Korea
}

female survivors, concerns include early-onset menopause and treatment-related infertility [4].

The need for female survivors to perform family planning is increasing. Care providers recommend that women wait from 6 months to 2 years after finishing chemotherapy before becoming pregnant to avoid adverse effects on the infant [5]. The long-term effects of repeated exposure to anticancer drugs remain unclear; however, most animal studies have used single or shortterm exposures to investigate adverse effects on ovarian function and their mechanisms. Reports on the mechanisms of chronic ovarian dysfunction after repeated cancer treatment are lacking. 
Cyclophosphamide (Cy) is a widely used alkylating agent that is toxic to both cancer cells and reproductive cells $[6,7]$. Cy exposure directly and indirectly leads to apoptosis by inducing DNA damage, suppressing proliferation, and causing mitochondrial dysfunction, resulting in diminished ovarian reserves [8-11]. A previous study showed that potent regulatory factors can persist or prevent acute ovarian toxicity induced by short-term $\mathrm{Cy}$ treatment [12]. Studies are needed to understand the molecular mechanism and changes in gene expression under chronic impaired conditions following rigorous Cy treatment. This may help in the prevention of the extended toxic effects of $\mathrm{Cy}$ treatment. To address the chronic effects of repeated Cy treatment, we evaluated ovarian function 4 weeks after the cessation of $\mathrm{Cy}$ exposure and investigated the molecular mechanisms underlying chronic ovarian damage.

\section{Methods}

Mice

Experimental animal protocols were approved by the Institutional Animal Care and Use Committee at Korea Institute of Oriental Medicine (19-019, Daejeon, Korea). Eight-week-old female C57BL/6 mice (18-20 g) were obtained from Narabiotech (Pyeongtaek, Korea) and housed under specific pathogen-free conditions. Animals were randomly divided into two groups and administered intraperitoneal injections of saline without $(n=12)$ or with $100 \mathrm{mg} / \mathrm{kg}$ Cy (Sigma-Aldrich, St. Louis, USA) six times over 2 weeks $(n=12)$. The mice were sacrificed 4 weeks after the final $\mathrm{Cy}$ injection. This timeframe was selected because it provides sufficient time for newly recruited primordial follicles to complete the preantral period [13]. Blood was collected from the inferior vena cava of mice anesthetized with $1.2 \%$ avertin $(0.6 \mathrm{~mL} /$ mouse, SigmaAldrich). Each mouse was euthanized by cervical dislocation to collect ovaries and oocytes after blood collection. The ovaries were removed, weighed, and immediately fixed in $4 \%$ paraformaldehyde (Biosesang, Seongnam, Korea).

\section{Hormonal assessment by enzyme-linked immunosorbent assay (ELISA)}

Sera separated from the blood samples were frozen at $70{ }^{\circ} \mathrm{C}$ until analysis. The concentration of anti-Müllerian hormone (AMH) was measured by ELISA (MyBiosource, San Diego, CA, USA) in triplicate according to a standard protocol and the manufacturers' instructions. The inter-assay coefficient of variation was $<10 \%$ and sensitivity was $0.19 \mathrm{ng} / \mathrm{mL}$.

\section{Histological assessment of ovarian follicles}

The whole ovaries were serially sectioned to $5-\mu \mathrm{m}$ thickness and stained with hematoxylin and eosin. Primordial, primary, secondary, and preovulatory follicles with visible oocytes were counted in every fifth stained section to avoid counting the same follicle twice. The follicle stage was classified as previously described [14, 15]: primordial follicles had a single flat layer of granulosa cells surrounding the oocyte, primary follicles had a single cuboidal granulosa cell layer, secondary follicles had at least two granulosa cell layers and a theca cell layer, and preovulatory follicles had a complete antrum and theca cell layer.

\section{Assessment of oocyte quality}

Cyclophosphamide- or saline-injected mice were superovulated via intraperitoneal injection of $5 \mathrm{IU}$ pregnant mare's serum gonadotropin (Prospec, Rehovot, Israel), followed by $5 \mathrm{IU}$ human chorionic gonadotropin (hCG, Prospec) at $48 \mathrm{~h}$ later. Oocytes were collected $18 \mathrm{~h}$ posthCG injection in preincubated Human Tubal Fluid medium (Irvine scientific, CA, USA). Oocytes were fixed in $4 \%$ paraformaldehyde and permeabilized in $0.5 \%$ Triton X-100 (Sigma-Aldrich) for $10 \mathrm{~min}$. Oocytes were blocked in phosphate-buffered saline containing 3\% bovine serum albumin (Genedepot, Katy, TX, USA), and then incubated with rabbit anti- $\alpha$-tubulin antibody (1: 200, Cell Signaling Technologies, Danvers, MA, USA). Oocytes were mounted with VECTASHIELD Antifade Mounting Medium with 4'6'-diamidino-2-phenylindole (DAPI, Vector Laboratories, Burlingame, CA, USA) to visualize the chromosomes, and observed by fluorescence microscopy (Olympus BX51, Tokyo, Japan). Oocytes with well-organized, bipolar spindles and chromosomes that were tightly aligned at the metaphase plate were scored as normal. Oocyte quality was also evaluated by measuring morphometrical parameters, including the complete oocyte, ooplasm, and perivitelline space (PVS) using NISelements BR 4.60.00 software (Nikon, Tokyo, Japan) [16].

\section{Microarray analysis}

Ovaries from $\mathrm{Cy}$ - or saline-injected mice were collected, and total RNA was extracted using the RNeasy Mini kit (Qiagen, Hilden, Germany) according to the manufacturer's instructions. The purity and integrity of the extracted RNA were evaluated using a NanoDrop ND1000 UV-Vis Spectrophotometer (Thermo Fisher Scientific, Waltham, MA, USA). All samples were of high purity (optical density $(\mathrm{OD})_{260} / \mathrm{OD}_{280}>2.00$ ) and integrity (RNA integrity number $>7.0$ ). Hybridization on GeneChip Mouse Gene 2.0 ST arrays (Affymetrix) was controlled using GeneChip Command Console Software (AGCC, Affymetrix, Santa Clara, CA, USA). We used Affymetrix Expression Console 1.4 Software for basic data extraction (CEL files) and quality control metrics. A fold change value $>2.0$ and a $p$-value $<0.05$ were used as thresholds to identify differentially expressed genes 
(DEGs). Functional annotation of the DEGs was performed using the Database for Annotation, Visualization and Integrated Discovery version 6.8 (https://david. ncifcrf.gov/hom.jsp). Gene ontology (GO) analysis was performed to identify potential functions of DEGs in the biological process, molecular function, and cellular component categories [17].

\section{Statistical analyses}

Data are presented as means \pm standard deviation (SD). The statistical significance of differences between the two groups was determined by Student's $t$-test using GraphPad Prism, version 8.4.0 (GraphPad, Inc., La Jolla, CA, USA). $P<0.05$ was considered as statistically significant.

\section{Results}

\section{Impaired physiological conditions endure after cy} exposure

Mice were monitored throughout the study and sacrificed to collect ovaries and blood 4 weeks after Cy treatment. The treated mice had significantly lower body weights than control mice (Fig. 1a). A significant loss of body weight has been associated with negative therapeutic responses [18]. We also measured AMH levels in the serum of $\mathrm{Cy}$ - and saline-injected mice (Fig. 1b). The AMH level was significantly decreased in Cy-injected mice, suggesting a decline in the number of growing follicles $(p<0.01)$.
Follicle loss after cessation of cy exposure

To investigate the side effects of rigorous Cy exposure on the ovaries, we performed histological analysis of isolated ovaries 4 weeks after Cy treatment. Entire follicles were damaged, and the number of follicles at all stages was significantly decreased (Fig. 2a, $p<0.05$ ). The proportions of primordial and preovulatory follicles were significantly decreased and increased, respectively (Fig. $2 \mathrm{~b}, p<0.01)$. The decrease in primordial follicles may have been due to a combination of damage and growth activation. Although surviving granulosa cells in the growing follicles secreted $\mathrm{AMH}$, its level was low, and only a small number of growing follicles survived and were activated within one menstrual cycle.

\section{Cy-induced impairment of oocyte quantity and quality is irreversible}

To investigate the effects of rigorous Cy exposure on oocytes, mice were hormonally superovulated. Oocytes were collected from the oviducts $18 \mathrm{~h}$ post-hCG, and their quantity and quality were assessed.

As expected, the total number of retrieved oocytes and number that matured to metaphase II (MII) were both significantly decreased (Fig. 3a and b, $p<0.05$ ). The MII oocytes of Cy-injected mice displayed increased chromosomal abnormalities and spindle misalignments compared to control oocytes (Fig. 3c, $p<0.001$ ).

Analysis of the morphology of Cy-treated oocytes revealed that the surrounding zona pellucida $(\mathrm{ZP})$ was

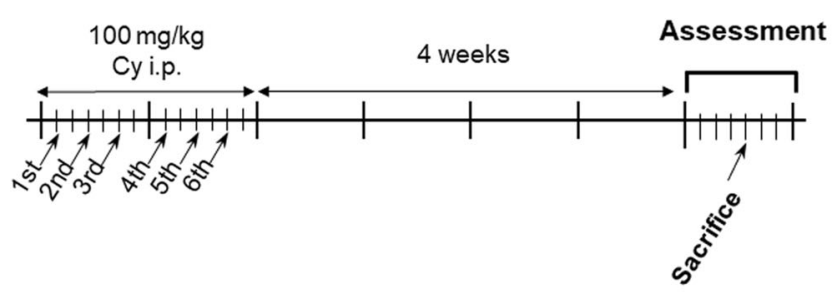

A

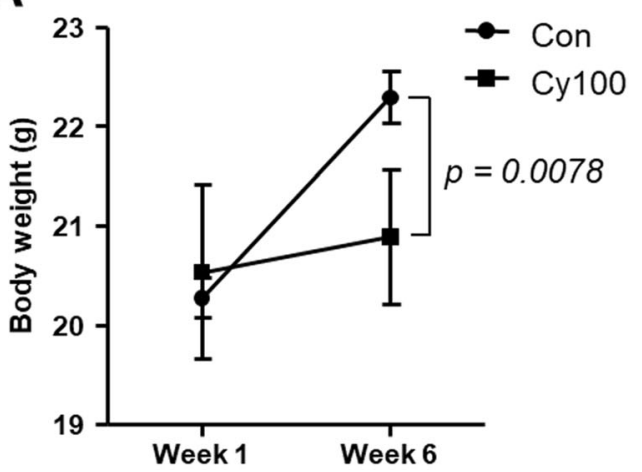

B

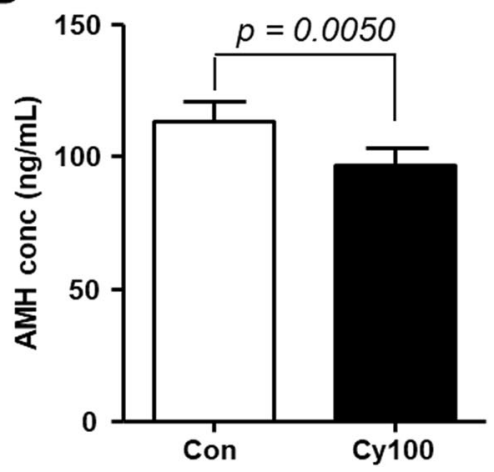

Fig. 1 Body weights and serum AMH levels 4 weeks after Cy exposure Mice were injected with Cy $(n=5)$ or saline $(n=5)$ for 2 weeks, and then housed for 4 weeks before the mice and ovaries were weighed, and serum AMH levels were measured. a Mouse body weights in individual control and Cy-injected mice. b Serum AMH levels in each group. Data represent the mean \pm standard deviation. Statistical analysis was performed by Student's t-test 

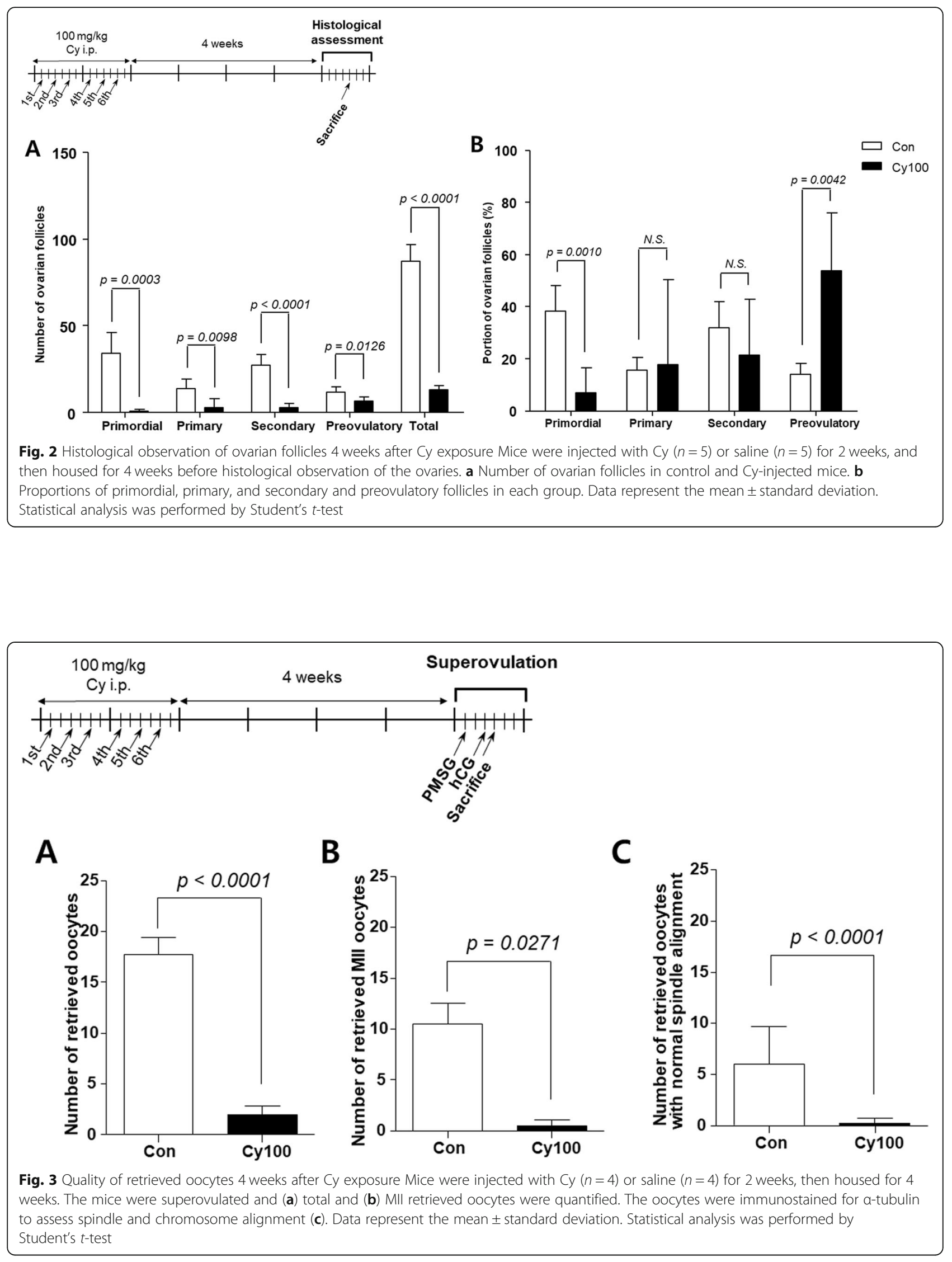
loosely compacted and less uniformly shaped than that in control oocytes (Fig. 4a). The area of the ooplasm was decreased in Cy-treated and control oocytes with a significantly increased PVS (Fig. 4b, $p<0.0001$ ). Abnormal PVS morphology is a negative indicator of an oocyte's developmental potential and has been linked to lower fertilization rates $[19,20]$. These results indicate that even after chemotherapy ends, residual $\mathrm{Cy}$ metabolites or surviving follicles with damaged granulosa cells can impair oocyte viability and quality in response to superovulation.

\section{Gene expression is continuously altered in response to repeated cy exposure}

We next performed microarray experiments to analyze and compare the RNA expression patterns in ovaries from $\mathrm{Cy}$ - or saline-injected mice. Hierarchical clustering analysis revealed marked differences among the two mouse groups (Fig. 5a). Of the 41,345 genes detected, 46 were significantly different between the two groups (Fig. $5 \mathrm{~b})$. Of these, seven genes (15.2\%) were upregulated and 39 genes (84.8\%) were downregulated in Cy-injected mice compared with control mice (Tables 1 and 2). Interestingly, the expression profiles of genes associated with fertilization and ovarian follicle development, such as ZP glycoprotein 2 and 3 ( $Z p 2$ and $Z p 3$ ); solute carrier family 18, member 2 (Slc18a2); WEE1 homolog 2 (Wee2); NLR family, pyrin domain containing 5 (Nlrp5) and 2'-5' -oligoadenylate synthetase $1 \mathrm{~d}$ and 1e (Oas1d and Oas1e), were changed. GO analysis revealed that in molecular functions, the DEGs were enriched in protein binding, acrosin binding, and 2'5'-oligoadenylate synthetase activity (Table 3 ). In biological process, enriched GO terms included ovarian follicle development, oogenesis, binding of sperm to $\mathrm{ZP}$, and immune response (Table 3). For cellular components, GO analysis revealed that the DEGs were enriched in GO terms such as cytoplasm, secretory granule, extracellular region, and matrix (Table 3).

\section{Discussion}

Currently, young women diagnosed with cancer have a greater chance of long-term survival than ever before. However, successful survivorship includes maintaining a high quality of life after cancer diagnosis and treatment [21], and lifesaving treatments such as chemotherapy, radiation, and surgery can impact survivors by impairing their reproductive and endocrine

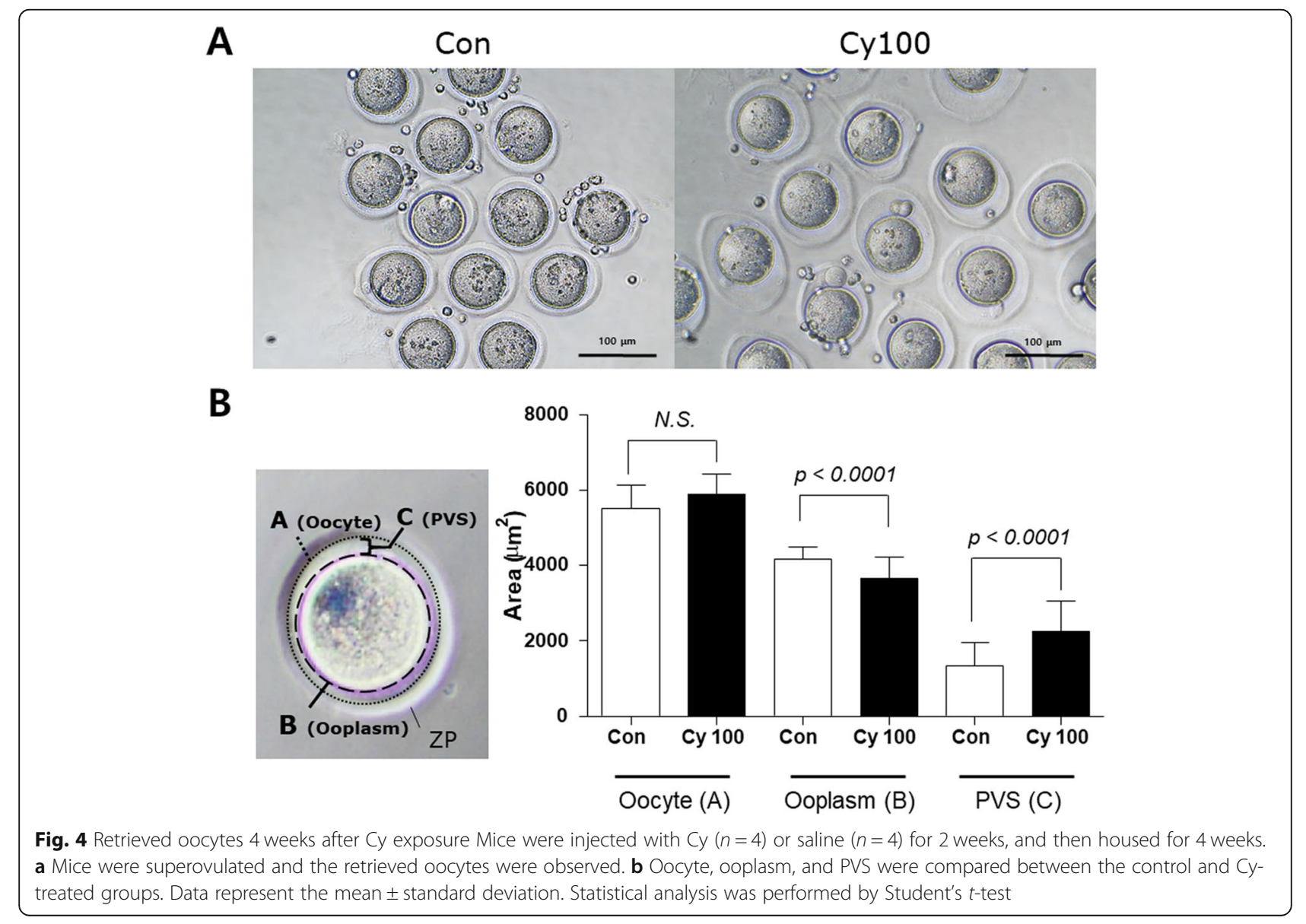




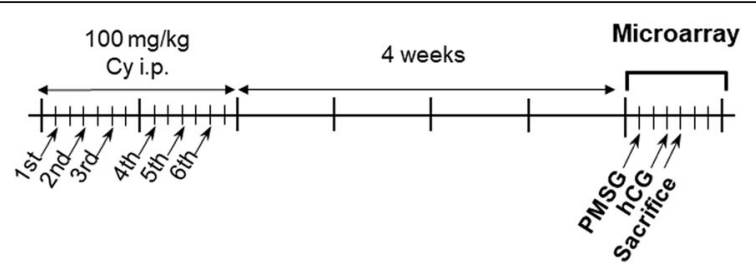

A

B
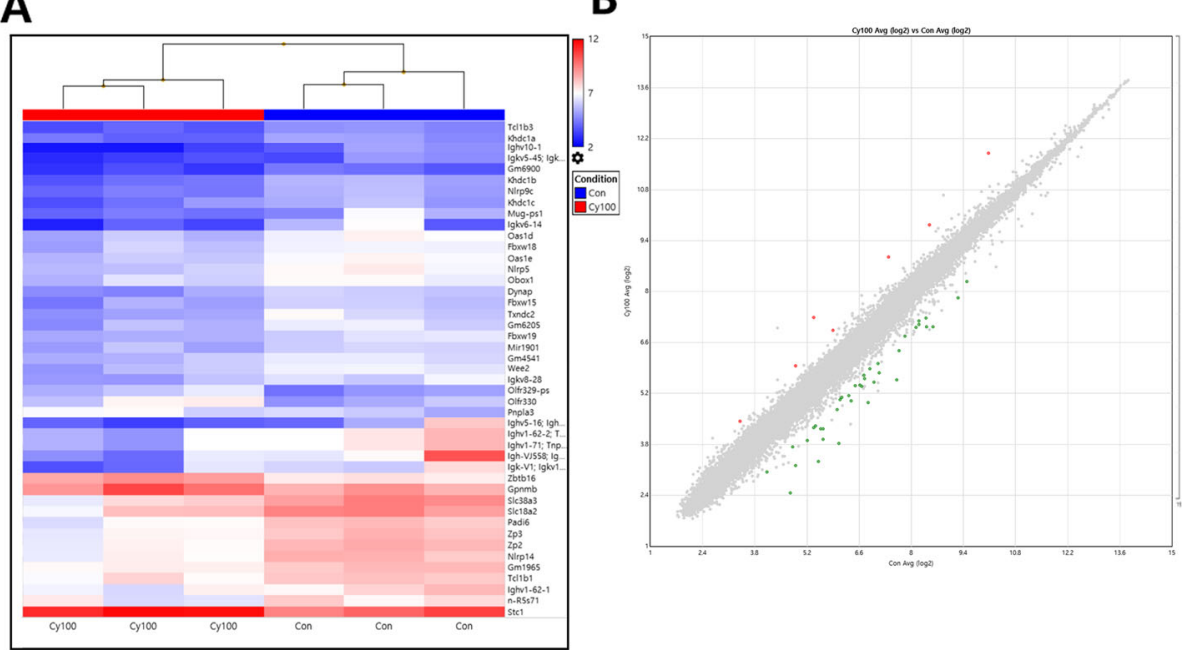

Fig. 5 Hierarchical clustering and analysis of DEGs Ovaries from mice injected with $C y(n=3)$ or saline $(n=3)$ were used for transcriptomic analysis. Microarrays were performed to compare ovarian gene expression 4 weeks after Cy exposure to that in control mice. a Hierarchical clustering among microRNA expression profiles. b Significantly upregulated and downregulated genes are shown as green and red

dots, respectively

health. Patients exposed to several months of rigorous chemotherapy can suffer from infertility or premature ovarian failure. In addition, patients who retain fertility after cancer therapy have increased risk factors for fetal and maternal complications during subsequent pregnancies [22]. As fertility issues in cancer survivorship have become increasingly important, additional studies are needed to evaluate these effects. Most studies examining cancer therapy-related infertility have used mouse models induced by single or shortterm exposure to anticancer agents, which is typically not performed in the clinic [3]. To consider the pathology of chronic ovarian impairment in young cancer survivors, we repeatedly administered $\mathrm{Cy}$ and analyzed physiological conditions at 4 weeks after treatment completion.

Cy exposure leads to deterioration of oocyte quality $[23,24]$. Koike et al. reported a decrease in the number of retrieved oocytes, whereas the rates of fertilization and blastocyst development were similar compared to those in controls at 2 weeks after single $400 \mathrm{mg} / \mathrm{kg}$ Cy administration in mice [25]. However, the mouse model following single exposure of $\mathrm{Cy}$ did not reflect the clinical situation regarding the extent of damage to the follicle and oocyte quality in oocytes and embryos after rigorous $\mathrm{Cy}$ treatment.

Table 1 Upregulated genes in Cy-exposed mice

\begin{tabular}{llll}
\hline Fold Change & $\boldsymbol{p}$-value & Gene Symbol & Description \\
\hline 3.76 & 0.0128 & Olfr330 & Olfactory receptor 330 \\
3.33 & 0.0014 & Stcl & Stanniocalcin 1 \\
2.97 & $1.40 \mathrm{E}-05$ & Zbtb16 & zinc finger and BTB domain containing 16 \\
2.53 & 0.0182 & Gpnmb & Glycoprotein (transmembrane) nmb \\
2.08 & 0.0068 & Olfr329-ps & Olfactory receptor 329, pseudogene \\
2.07 & 0.0298 & Pnpla3 & Patatin-like phospholipase domain containing 3 \\
2.04 & 0.0024 & Gm24078 & Predicted gene, 24,078 \\
\hline
\end{tabular}

Genes were significantly upregulated in Cy-injected mice when they displayed $>2.0$-fold expression compared to in the control $(p<0.05)$ 
Table 2 Downregulated genes in Cy-exposed mice

\begin{tabular}{|c|c|c|c|}
\hline Fold Change & $p$-value & Gene Symbol & Description \\
\hline 4.92 & 0.0009 & Ighv10-1 & Immunoglobulin heavy variable $10-1$ \\
\hline 4.71 & 0.0402 & lgk-V1 & Immunoglobulin kappa chain variable 1 \\
\hline 4.49 & 0.0204 & $\operatorname{lgkv6-14}$ & Immunoglobulin kappa variable 6-14 \\
\hline 4.05 & 0.0095 & lghv1-62-2 & Immunoglobulin heavy variable $1-62-2$ \\
\hline 4.05 & 0.0095 & Ighv1-71 & Immunoglobulin heavy variable 1-71 \\
\hline 3.71 & 0.0235 & Igh-VJ558 & Immunoglobulin heavy chain (J558 family) \\
\hline 3.25 & 0.0402 & lghv5-16 & Immunoglobulin heavy variable 5-16 \\
\hline 3.19 & 0.0184 & $\operatorname{lgkv5-45}$ & Immunoglobulin heavy chain variable $5-45$ \\
\hline 2.93 & 0.0003 & Nlrp14 & NLR family, pyrin domain containing 14 \\
\hline 2.79 & 0.0003 & Oas1d & 2-5 oligoadenylate synthetase 1D \\
\hline 2.70 & 0.0009 & Slc38a3 & solute carrier family 38 , member 3 \\
\hline 2.65 & 0.0203 & Mug-ps1 & Murinoglobulin, pseudogene 1 \\
\hline 2.63 & 0.0049 & lgkv8-28 & Immunoglobulin kappa variable 8-28 \\
\hline 2.59 & $3.59 \mathrm{E}-05$ & Zp2 & zona pellucida glycoprotein 2 \\
\hline 2.56 & 0.0001 & Nlrp5 & NLR family, pyrin domain containing 5 \\
\hline 2.54 & 0.0002 & Khdc1b & $\mathrm{KH}$ domain containing $1 \mathrm{~B}$ \\
\hline 2.45 & 0.0009 & Khdcla & $\mathrm{KH}$ domain containing $1 \mathrm{~A}$ \\
\hline 2.45 & 0.0266 & $n-R 5 s 71$ & nuclear encoded rRNA 5S 71 [Source:MGI Symbol;Acc:MGl:4421916 \\
\hline 2.41 & 0.0056 & Gm6205 & predicted gene 6205 \\
\hline 2.38 & 0.0007 & Dynap & dynactin associated protein \\
\hline 2.31 & 0.0048 & Slc18a2 & solute carrier family 18 (vesicular monoamine), member 2 \\
\hline 2.27 & 0.0023 & Gm4541 & Predicted gene 4541 \\
\hline 2.25 & 0.0025 & Txndc2 & Thioredoxin domain containing 2 \\
\hline 2.2 & 0.0021 & Wee2 & WEE1 homolog 2 \\
\hline 2.19 & 0.0004 & Nlrp9c & NLR family, pyrin domain containing $9 \mathrm{C}$ \\
\hline 2.18 & 0.165 & Khdc1c & $\mathrm{KH}$ domain containing $1 \mathrm{C}$ \\
\hline 2.16 & 0.0003 & Padi6 & peptidyl arginine deiminase, type $\mathrm{VI}$ \\
\hline 2.15 & $8.81 \mathrm{E}-05$ & Gm1965 & predicted gene 1965 \\
\hline 2.14 & 0.005 & Obox1 & Oocyte specific homeobox 1 \\
\hline 2.14 & 0.007 & Tcl1b1 & T cell leukemia/lymphoma 1B, 1 \\
\hline 2.12 & 0.0002 & Tcl1b3 & T cell leukemia/lymphoma 1B, 3 \\
\hline 2.12 & 0.0036 & Gm6900 & Predicted gene 6900 [Source:MGI Symbol;Acc:MGI:3645052] \\
\hline 2.11 & 0.0003 & Fbxw19 & F-box and WD-40 domain protein 19 \\
\hline 2.08 & 0.0082 & Fbxw15 & F-box and WD-40 domain protein 15 \\
\hline 2.07 & 0.0193 & lghv1-62-1 & Immunoglobulin heavy variable $1-62-1$ \\
\hline 2.05 & 0.0025 & Fbxw18 & F-box and WD-40 domain protein 18 \\
\hline 2.05 & 0.0084 & Mir1901 & microRNA 1901 \\
\hline 2.02 & 0.0003 & Zp3 & zona pellucida glycoprotein 3 \\
\hline 2.31 & 0.0053 & Oas1e & 2-5 oligoadenylate synthetase $1 \mathrm{E}$ \\
\hline
\end{tabular}

Genes were significantly downregulated in Cy-injected mice when they displayed $>2.0$-fold differences compared to the control $(p<0.05)$

Interestingly, both follicles and oocytes were susceptible to Cy-induced damage even after the 4 weeks had passed, allowing sufficient time for the generation of new preovulatory follicles [13]. Only a small number of oocytes were retrieved, which had phenotypic indications of low fertilization potential. This leads to poor reproductive outcomes such as a high risk of non-viable fetuses and malformation at 4 weeks after Cy exposure [26]. 
Table 3 Functional annotation of differentially expressed genes

\begin{tabular}{lll}
\hline Category & Term & EASE Score \\
\hline GOTERM_CC_DIRECT & GO:0030141 secretory granule & 0.0001631 \\
GOTERM_BP_DIRECT & GO:0001541 ovarian follicle development & 0.0017886 \\
GOTERM_CC_DIRECT & GO:0005737 cytoplasm & 0.0021057 \\
GOTERM_MF_DIRECT & GO:0032190 acrosin binding & 0.0029206 \\
GOTERM_MF_DIRECT & GO:0005515 protein binding & 0.0079809 \\
GOTERM_MF_DIRECT & GO:0001730 2'-5'-oligoadenylate synthetase activity & 0.0106698 \\
GOTERM_BP_DIRECT & GO:0006828 manganese ion transport & 0.0164696 \\
GOTERM_CC_DIRECT & GO:0005576 extracellular region & 0.0225659 \\
GOTERM_BP_DIRECT & GO:0045893 positive regulation of transcription, DNA-templated & 0.0244882 \\
GOTERM_CC_DIRECT & GO:0005771 multivesicular body & 0.0276672 \\
GOTERM_CC_DIRECT & GO:0031012 extracellular matrix & 0.032228 \\
GOTERM_BP_DIRECT & GO:0006955 immune response & 0.0358449 \\
GOTERM_CC_DIRECT & GO:0005578 proteinaceous extracellular matrix & 0.0367763 \\
GOTERM_BP_DIRECT & GO:0048477 oogenesis & 0.0369613 \\
GOTERM_BP_DIRECT & GO:0007339 binding of sperm to zona pellucida & 0.0390946 \\
\hline
\end{tabular}

GO Gene ontology and KEGG Kyoto Encyclopedia of Genes and Genomes analysis was performed to identify potential functions of the differentially expressed genes in the MF molecular function, $B P$ biological process, and CC cellular component categories

There is limited information regarding the effects of $\mathrm{Cy}$ in the ovaries. Cy is thought to act as a direct ovotoxin that destroys dormant primordial follicles and activates quiescent primordial follicles by inducing apoptosis in pregranulosa cells and oocytes [27]. Cy exposure also generates increased reactive oxygen species in oocytes, resulting in mitochondrial dysfunction and disrupting the meiotic spindle $[23,28]$.

To examine whether the adverse effects of rigorous chemotherapy persisted after cancer treatment ends, we performed microarray and bioinformatic analyses on ovaries 4 weeks after $\mathrm{Cy}$ exposure. In the microarray data, seven genes were found to be upregulated. Of them, Zbtb1 is a member of the Krüeppel C2H2-type zinc-finger protein family and regulated by the PI3K/PTEN/AKT pathway, which has a critical role in regulating dormancy and initial primordial follicle activation [29]. However, exposure to Cy disturbs this balance by destroying growing follicles or activating the PI3K/PTEN/Akt pathway, causing reservoir "burnout" [30, 31].

A total of 39 downregulated DEGs associated with folliculogenesis and oogenesis are involved in the prolonged effects of repeated Cy treatment. WEE2, one of the oocytespecific kinase, is responsible for the follicular development, oocyte meiotic regulation, and fertilization in humans and mice [32, 33]. Reduced WEE2 levels induce fertilization failure and abnormal blastocyst formation [34]. Slc18a2 is highly expressed in granulosa cells of growing follicles and its downregulation indicates that granulosa cells were damaged by $\mathrm{Cy}$ exposure [35]. Additionally, expression of $O A S 1 D$, which regulates the translational regulator of newborn ovary homeobox gene (Nobox), was decreased, leading to rapid follicle loss after birth [36]. Taken together, altered gene expression continuously impaired ovarian follicle development even after Cy exposure was complete.

The DEGs also included oocyte-specific genes associated with fertilization, including $Z p 1,2$, and 3, which are critical for proper organization of the ZP surrounding oocytes and showed decreased expression 4 weeks after $\mathrm{Cy}$ exposure. Consistent with the microarray data, morphological observation revealed a loosely compacted ZP and enlarged PVS, which can affect fertility [37].

The microarray data indicate that genetic regulation in ovaries remains impaired 4 weeks after repeated Cy exposure. We found that impaired follicular growth correlated with oocyte abnormalities caused by rigorous $\mathrm{Cy}$ treatment. However, in our study, we did not determine whether these abnormal oocytes are directly caused by $\mathrm{Cy}$ and/or indirectly through other cells such as granulosa cells, and assessment of the fertilization potential of Cy-damaged oocytes requires further studies. In recent decades, several studies have been conducted to develop strategies for protecting fertility from the effects of chemotherapeutic drugs, but they have been performed during chemotherapy in animal models [38]. Our results suggest that, for young cancer survivors, persistent treatment is required to prevent chronic damage to the ovaries after chemotherapy ends.

\section{Conclusion}

We found that ovarian cell damage induced by repeated Cy treatment continuously alters the expression of genes associated with fertility and has persistent effects on ovarian function, resulting in diminished ovarian reserves even after the completion of chemotherapy. 
Studies to prevent chronic damage to the ovaries and/or restore their function are required to ensure fertility preservation in cancer survivors.

\section{Abbreviations}

AMH: Anti-Müllerian hormone; Cy: Cyclophosphamide; DEGs: Differentially expressed genes; GO: Gene ontology; hCG: Human chorionic gonadotropin; KEGG: Kyoto Encyclopedia of Genes and Genomes; Nobox: Newborn ovary homeobox gene; NIrp5: NLR family, pyrin domain containing 5; Oas 1d: 2'-5'oligoadenylate synthetase 1d; Oas1e: 2'-5'-oligoadenylate synthetase 1e: PVS: Perivitelline space; PMSG: Pregnant mare's serum gonadotropin; SIc18a2: Solute carrier family 18, member 2; Wee2: WEE1 homolog 2

\section{Acknowledgments}

Not applicable.

\section{Authors' contributions}

All authors have read and approved the manuscript. JK conceived the study, performed experiments, and wrote and revised the manuscript. SY performed experiments, revised the manuscript, and is responsible for correspondence.

\section{Funding}

This study was financially supported by a project grant from the Korea Institute of Oriental Medicine (KSN2013240). The study funder had no further role in the study design, data collection, analyses, interpretation of results, writing of the article, or the decision to submit it for publication.

\section{Availability of data and materials}

All data generated and analyzed during this study are included in this article. The datasets generated and/or analysed during the current study are available from the corresponding author on reasonable request.

\section{Ethics approval and consent to participate}

All the experiments and analyses were conducted in accordance with the relevant guidelines and regulations. Experimental animal protocols were approved by the Institutional Animal Care and Use Committee at Korea Institute of Oriental Medicine (19-019, Daejeon, Korea). No permission was necessary to collect the specimens in our study.

\section{Consent for publication}

I understand that the text and any pictures published in the article will be freely available on the internet and may be seen by the general public. I have been offered the opportunity to read the manuscript.

\section{Competing interests}

The authors declare no conflicts of interest.

Received: 27 August 2020 Accepted: 16 December 2020 Published online: 07 January 2021

\section{References}

1. Lin A, Giuliano CJ, Palladino A, John KM, Abramowicz C, Yuan ML, Sausville EL, Lukow DA, Liu L, Chait AR, Galluzzo ZC, Tucker C, Sheltzer JM. Off-target toxicity is a common mechanism of action of cancer drugs undergoing clinical trials. Sci Transl Med. 2019;11(509):eaaw8412. https://doi.org/10.1126/ scitranslmed.aaw8412.

2. Wang Y, Qi X, Li D, Zhu T, Mo X, Li J. Anticancer efficacy and absorption, distribution, metabolism, and toxicity studies of aspergiolide a in early drug development. Drug Des Devel Ther. 2014;8:1965-77. https://doi.org/10.2147/ dddt.S64989.

3. Hulvat MC, Jeruss JS. Maintaining fertility in young women with breast cancer. Curr Treat Options in Oncol. 2009;10(5-6):308-17. https://doi.org/10. 1007/s11864-010-0116-2.

4. Letourneau JM, Ebbel EE, Katz PP, Oktay KH, McCulloch CE, Ai WZ, Chien AJ, Melisko ME, Cedars MI, Rosen MP. Acute ovarian failure underestimates agespecific reproductive impairment for young women undergoing chemotherapy for cancer. Cancer. 2012;118(7):1933-9. https://doi.org/10. 1002/cncr.26403.
5. Lawrenz B, Banys M, Henes M, Neunhoeffer E, Grischke EM, Fehm T. Pregnancy after breast cancer: case report and review of the literature. Arch Gynecol Obstet. 2011;283(4):837-43.

6. Handolias D, Quinn M, Foo S, Mileshkin L, Grant P, Dutu G, Rischin D. Oral cyclophosphamide in recurrent ovarian cancer. Asia Pac J Clin Oncol. 2016; 12(1):e154-60. https://doi.org/10.1111/ajco.12074.

7. Madden JA, Hoyer PB, Devine PJ, Keating AF. Involvement of a volatile metabolite during phosphoramide mustard-induced ovotoxicity. Toxicol Appl Pharmacol. 2014;277(1):1-7. https://doi.org/ 10.1016/j.taap.2014.03.006.

8. Ludovini V, Antognelli C, Rulli A, Foglietta J, Pistola L, Eliana R, Floriani I, Nocentini G, Tofanetti FR, Piattoni S, Minenza E, Talesa VN, Sidoni A, Tonato M, Crino L, Gori S. Influence of chemotherapeutic drug-related gene polymorphisms on toxicity and survival of early breast cancer patients receiving adjuvant chemotherapy. BMC Cancer. 2017;17(1):502. https://doi. org/10.1186/s12885-017-3483-2.

9. Madden JA, Keating AF. Ovarian xenobiotic biotransformation enzymes are altered during phosphoramide mustard-induced ovotoxicity. Toxicol Sci. 2014;141(2):441-52. https://doi.org/10.1093/toxsci/kfu146.

10. Himelstein-Braw R, Peters H, Faber M. Morphological study of the ovaries of leukaemic children. Br J Cancer. 1978;38(1):82-7. https://doi.org/10.1038/bjc. 1978.166.

11. Shah MA, Schwartz GK. Cell cycle-mediated drug resistance: an emerging concept in cancer therapy. Clin Cancer Res. 2001;7(8):2168-81.

12. Kalich-Philosoph L, Roness H, Carmely A, Fishel-Bartal M, Ligumsky H, Paglin S, Wolf I, Kanety H, Sredni B, Meirow D. Cyclophosphamide triggers follicle activation and "burnout"; AS101 prevents follicle loss and preserves fertility. Sci Transl Med. 2013;5(185):185ra62. https://doi.org/10.1126/scitrans/med. 3005402.

13. McGee EA, Hsueh AJ. Initial and cyclic recruitment of ovarian follicles. Endocr Rev. 2000;21(2):200-14. https://doi.org/10.1210/edrv.21.2.0394.

14. Pedersen T, Peters H. Proposal for a classification of oocytes and follicles in the mouse ovary. J Reprod Fertil. 1968;17(3):555-7.

15. Myers M, Britt KL, Wreford NG, Ebling FJ, Kerr JB. Methods for quantifying follicular numbers within the mouse ovary. Reproduction. 2004;127(5):56980. https://doi.org/10.1530/rep.1.00095.

16. Balaban B, Urman B. Effect of oocyte morphology on embryo development and implantation. Reprod BioMed Online. 2006;12(5):608-15. https://doi.org/ 10.1016/s1472-6483(10)61187-X

17. Ren YM, Duan $Y H$, Sun $Y B$, Yang $T$, Tian MQ. Bioinformatics analysis of differentially expressed genes in rotator cuff tear patients using microarray data. J Orthop Surg Res. 2018;13(1):284. https://doi.org/10.1186/s13018-018-0989-5.

18. Gadducci A, Cosio S, Fanucchi A, Genazzani AR. Malnutrition and cachexia in ovarian cancer patients: pathophysiology and management. Anticancer Res. 2001;21(4b):2941-7.

19. Figueira R, de Almeida Ferreira Braga DP, Semião-Francisco L, Madaschi C, laconelli A Jr, Borges E Jr. Metaphase II human oocyte morphology: contributing factors and effects on fertilization potential and embryo developmental ability in ICSI cycles. Fertil Steril. 2010;94(3):1115-7. https://doi.org/10.1016/j.fertnstert.2009.11.039.

20. Setti AS, Figueira RC, Braga DP, Colturato SS, laconelli A Jr, Borges E Jr. Relationship between oocyte abnormal morphology and intracytoplasmic sperm injection outcomes: a meta-analysis. Eur J Obstet Gynecol Reprod Biol. 2011;159(2):364-70. https://doi.org/10.1016/ j.ejogrb.2011.07.031

21. Waimey KE, Smith BM, Confino R, Jeruss JS, Pavone ME. Understanding fertility in young female cancer patients. J Women's Health (Larchmt). 2015; 24(10):812-8. https://doi.org/10.1089/jwh.2015.5194.

22. Kort JD, Eisenberg ML, Millheiser LS, Westphal LM. Fertility issues in cancer survivorship. CA Cancer J Clin. 2014;64(2):118-34. https://doi.org/10.3322/ caac. 21205 .

23. Jeelani R, Khan SN, Shaeib F, Kohan-Ghadr HR, Aldhaheri SR, Najafi T, Thakur M, Morris R, Abu-Soud HM. Cyclophosphamide and acrolein induced oxidative stress leading to deterioration of metaphase II mouse oocyte quality. Free Radic Biol Med. 2017;110:11-8.

24. Nguyen QNZN, Liew SH, Findlay JK, Hickey M, Hutt KJ. Cisplatin- and cyclophosphamide-induced primordial follicle depletion is caused by direct damage to oocytes. Mol Hum Reprod. 2019;25(8):433-44. https://doi.org/10. 1093/molehr/gaz020.

25. Koike MKA, Kido K, Goto K, Kumasako Y, Nagaki M, Otsu E, Araki Y, Araki Y, Kawabe F, Kai Y, Utsunomiya T. Effects of cyclophosphamide administration 
on the in vitro fertilization of mice. Reprod Med Biol. 2018;17(3):262-7. https://doi.org/10.1002/rmb2.12099.

26. Meirow DEM, Lewis H, Nugent D, Gosden RG. Administration of cyclophosphamide at different stages of follicular maturation in mice: effects on reproductive performance and fetal malformations. Hum Reprod. 2001;16(4):632-7. https://doi.org/10.1093/humrep/16.4.632.

27. Kim SY, Cho GJ, Davis JS. Consequences of chemotherapeutic agents on primordial follicles and future clinical applications. Obstet Gynecol Sci. 2019; 62(6):382-90. https://doi.org/10.5468/ogs.2019.62.6.382.

28. Zhang M, ShiYang $X$, Zhang Y, Miao Y, Chen Y, Cui Z, Xiong B. Coenzyme Q10 ameliorates the quality of postovulatory aged oocytes by suppressing DNA damage and apoptosis. Free Radic Biol Med. 2019;143:84-94. https:// doi.org/10.1016/j.freeradbiomed.2019.08.002.

29. Zhou WSH, Zhang D, Dong J, Cheng W, Wang L, Teng Y, Yu Z. PTEN signaling is required for the maintenance of spermatogonial stem cells in mouse, by regulating the expressions of PLZF and UTF1. Cell Biosci. 2015;5: 42. https://doi.org/10.1186/s13578-015-0034-x.

30. Roness HGZ, Cohen Y, Meirow D. Ovarian follicle burnout: a universal phenomenon? Cell Cycle. 2013;12(20):3245-6. https://doi.org/10.4161/cc. 26358.

31. Luan YEM, Woodruff TK, Kim SY. Inhibitors of apoptosis protect the ovarian reserve from cyclophosphamide. J Endocrinol. 2019;240(2):243-56. https:// doi.org/10.1530/joe-18-0370.

32. Bonnet A, Servin B, Mulsant P, Mandon-Pepin B. Spatio-temporal gene expression profiling during in vivo early ovarian folliculogenesis: integrated transcriptomic study and molecular signature of early follicular growth. PLoS One. 2015;10(11):e0141482. https://doi.org/10.1371/journal.pone.0141482.

33. Bonnet A, Cabau C, Bouchez O, Sarry J, Marsaud N, Foissac S, Woloszyn F, Mulsant $P$, Mandon-Pepin B. An overview of gene expression dynamics during early ovarian folliculogenesis: specificity of follicular compartments and bi-directional dialog. BMC Genomics. 2013;14:904. https://doi.org/10. 1186/1471-2164-14-904.

34. Sang Q, Li B, Kuang Y, Wang X, Zhang Z, Chen B, Wu L, Lyu Q, Fu Y, Yan Z, Mao X, Xu Y, Mu J, Li Q, Jin L, He L, Wang L. Homozygous mutations in WEE2 cause fertilization failure and female infertility. Am J Hum Genet. 2018; 102(4):649-57. https://doi.org/10.1016/j.ajhg.2018.02.015.

35. Gallardo TD, John GB, Shirley L, Contreras CM, Akbay EA, Haynie JM, Ward SE, Shidler MJ, Castrillon DH. Genomewide discovery and classification of candidate ovarian fertility genes in the mouse. Genetics. 2007;177(1):179-94. https://doi.org/10.1534/genetics.107.074823.

36. Rajkovic A, Pangas SA, Ballow D, Suzumori N, Matzuk MM. NOBOX deficiency disrupts early folliculogenesis and oocyte-specific gene expression. Science. 2004;305(5687):1157-9. https://doi.org/10.1126/science. 1099755.

37. Gosden R, Lee B. Portrait of an oocyte: our obscure origin. J Clin Invest. 2010;120(4):973-83. https://doi.org/10.1172/jci41294.

38. Spears N, Lopes F, Stefansdottir A, Rossi V, De Felici M, Anderson RA, Klinger FG. Ovarian damage from chemotherapy and current approaches to its protection. Hum Reprod Update. 2019;25(6):673-93.

\section{Publisher's Note}

Springer Nature remains neutral with regard to jurisdictional claims in published maps and institutional affiliations.

Ready to submit your research? Choose BMC and benefit from:

- fast, convenient online submission

- thorough peer review by experienced researchers in your field

- rapid publication on acceptance

- support for research data, including large and complex data types

- gold Open Access which fosters wider collaboration and increased citations

- maximum visibility for your research: over $100 \mathrm{M}$ website views per year

At $\mathrm{BMC}$, research is always in progress.

Learn more biomedcentral.com/submissions 